1 Fundação Oswaldo Cruz (Fiocruz), Escola Nacional de Saúde Pública Sergio Arouca (Ensp), Departamento de Direitos Humanos, Saúde e

Diversidade Cultural. Rio de Janeiro (RJ) - Brasil. luciafsouto@yahoo.com.br

2 Fundação Oswaldo Cruz (Fiocruz), Escola Nacional de Saúde Pública Sergio Arouca (Ensp), Departamento de Direitos Humanos, Saúde e Diversidade Cultural. Rio de Janeiro (RJ) - Brasil.

mhelen@ensp.fiocruz.br

\section{Movimento da Reforma Sanitária Brasileira: um projeto civilizatório de globalização alternativa e construção de um pensamento pós-abissal}

\author{
The Brazilian Sanitary Reform Movement: a civilizatory project of \\ alternative globalization and construction of a post-abyssal thought
}

Lúcia Regina Florentino Souto', Maria Helena Barros de Oliveira²

RESUMO O objetivo deste artigo é compreender os desafios colocados à efetivação do direito à saúde, proclamado na Constituição de 1988, na perspectiva dos valores afirmados pelo projeto civilizatório do Movimento da Reforma Sanitária Brasileira (MRSB). Inicialmente destacamos a dimensão civilizatória do MRSB e enfatizamos o seu caráter contra-hegemônico, nas dimensões política e epistemológica. Demarca um processo constituinte de direitos e a criação/produção de um novo campo de conhecimento, a saúde coletiva, o que permite, na nossa opinião, alinhá-lo no pensamento pós-abissal, uma ecologia de saberes.

PALAVRAS-CHAVE Democracia; Direito à saúde; Reforma dos serviços de saúde; Saúde pública; Ecologia de saberes.

ABSTRACT The goal of this article is to understand the challenges to the effectuation of health rights, as stated in the 1988 Constitution, from the perspective of the civilizatory project of the Brazilian Movement for Sanitary Reform (MRSB). Initially we highlight the civilizational dimension of the MRSB and try to emphasize its counter-hegemonic character in the political and epistemological dimensions. Delimits a constituent process of rights and the creation/production of a new field of knowledge, Collective Health, which allows, in our opinion, align it into post-abyssal thought, an ecology of knowledge.

KEYWORDS Democracy; Right to health; Health care reform; Public health; Ecology of knowledge. 
Perguntei ao homem o que era o Direito. Ele me respondeu que era a garantia do exercício da possibilidade.

(Oswald de Andrade)

\section{Movimento da Reforma Sanitária Brasileira: um pensamento pós-abissal, uma ecologia de saberes}

Segundo Paim (2007, P. 21),

no Brasil, surgiu em meados da década de 70, um movimento postulando a democratização da saúde, justamente num período no qual novos sujeitos sociais emergiram nas lutas contra a ditadura.

O Movimento da Reforma Sanitária Brasileira (MRSB) constituiu-se no processo de amplas mobilizações da sociedade brasileira pela redemocratização. Expressou a indignação da sociedade frente as aviltantes desigualdades, a mercantilização da saúde (AROUCA, 2003) e, configurou-se como ação política concertada em torno de um projeto civilizatório de sociedade inclusiva, solidária, tendo a saúde como direito universal de cidadania.

A partir dessa compreensão é possível dialogar com algumas das reflexões de Santos (2007A, P. 3):

[...] que as linhas cartográficas abissais que demarcaram o Velho e o Novo mundo na era colonial subsistem estruturalmente no pensamento moderno ocidental e permanecem constitutivas das relações culturais excludentes mantidas no sistema mundial contemporâneo. A injustiça social global estaria associada à injustiça cognitiva global, de modo que a luta por uma justiça social global requer a construção de um pensamento 'pós-abissal'.
Destacamos dimensões do MRSB como, a dimensão civilizatória, a democrático participativa, a epistemológica que, no nosso entendimento, permitem alinhá-lo como constitutivo de um pensamento pós-abissal, uma ecologia de saberes sendo parte das disputas globais, históricas, políticas e epistemológicas. Conforme Santos (2007A, P. 3-4)

O pensamento moderno ocidental é um pensamento abissal. Consiste num sistema de distinções visíveis e invisíveis, sendo que as invisíveis fundamentam as visíveis. As distinções invisíveis são estabelecidas através de linhas radicais que dividem a realidade social em dois universos distintos: o universo 'deste lado da linha' e o universo 'do outro lado da linha'. A divisão é tal que 'o outro lado da linha' desaparece enquanto realidade, torna-se inexistente, e é mesmo produzido como inexistente. Inexistência significa não existir sob qualquer forma de ser relevante ou compreensível. Tudo aquilo que é produzido como inexistente é excluído de forma radical porque permanece exterior ao universo que a própria concepção aceite da inclusão considera como sendo o Outro.

Na dimensão civilizatória, destacamos o caráter contra-hegemônico do projeto civilizatório do MRSB, ao afirmar a saúde como direito universal de cidadania, na contramão do projeto de globalização neoliberal com sua agenda de restrição de direitos, de focalização das políticas sociais, preconizadas pelas agências internacionais (Banco Mundial, Fundo Monetário Internacional), como única saída para a crise fiscal das décadas de 1970/1980.

$\mathrm{Na}$ dimensão democrática participativa, destacamos o processo constituinte de ampla e plural participação, marca indelével da construção do direito à saúde no Brasil, expressa no texto da Constituição de 1988.

$\mathrm{Na}$ dimensão epistemológica, a criação do plural e aberto campo da saúde coletiva que vem possibilitando a emergência 
de múltiplos saberes, e de uma justiça cognitiva pelo exercício real de uma ecologia de saberes, constituindo-se como um dos valores do projeto do MRSB de resistência e construção de alternativas, frente ao projeto de uma globalização neoliberal excludente e monocultural.

A construção do campo da saúde coletiva, invenção genuinamente brasileira, tem origem a partir da crítica realizada à medicina preventiva, por Arouca (2003) em sua tese de doutorado ' $\mathrm{O}$ dilema preventivista'. Paim (2007, P. 20) ressalta que

a partir da crítica à medicina preventiva ocorreu uma aproximação teórico-conceitual com a medicina social, evoluindo para a constituição da saúde coletiva, enquanto campo científico comprometido com a prática teórica.

A crítica realizada por Arouca (2003) ao discurso liberal da medicina preventiva, instigou o desafio à sua superação, propiciando o ineditismo da criação compartilhada do campo da saúde coletiva no Brasil. A compreensão da determinação social do processo saúde/doença, entre outros conceitos, produziu repercussões na reflexão política, nas múltiplas práticas de saberes da saúde em contraste com a hegemonia monocultural do paradigma biomédico. Como comenta Santos (2010, P. 157),

A ecologia de saberes procura dar consistência epistemológica ao saber propositivo. Trata-se de uma ecologia porque assenta no reconhecimento da pluralidade de saberes heterogêneos, da autonomia de cada um deles e da articulação sistêmica, dinâmica e horizontal entre eles. A ecologia de saberes assenta na independência complexa entre os diferentes saberes que constituem o sistema aberto de conhecimento em processo constante de criação e renovação. O conhecimento é interconhecimento, é reconhecimento, é autoconhecimento.
Para Santos (2010, P. 157) como o conhecimento científico não está distribuído socialmente de forma equitativa, as intervenções no real que privilegiam são as dos grupos sociais que detêm o conhecimento científico. "A injustiça social assenta na injustiça cognitiva. A ecologia de saberes é a epistemologia da luta contra a injustiça cognitiva". O campo da saúde coletiva permitiu substituir monoculturas por ecologias o que nos permite operar com o que Santos (2010) denomina sociologia das ausências, ou seja, tornar presente as experiências desperdiçadas, através de múltiplas formas de produção social de ausências como: $o$ ignorante, o residual, o inferior, o local, e o improdutivo. Em cada um desses domínios, a sociologia das ausências se exerce substituindo monoculturas por ecologias.

O 'ignorante': nesse domínio trabalha com o princípio da incompletude dos saberes, não há ignorância em geral nem saber em geral; o 'residual': nesse domínio confronta a lógica da monocultura do tempo linear partindo da ideia de tempos e temporalidades distintos para cada sociedade e que culturas distintas geram diferentes regras temporais, o que permite libertar as práticas sociais do estatuto residual atribuído pelo cânone temporal hegemônico. No domínio do 'inferior', confronta a desqualificação colonizadora que identifica a diferença com desigualdade, propondo nova articulação entre os princípios da igualdade e diferença, a ecologia de diferenças iguais feita de reconhecimentos recíprocos. No domínio do 'local', a sociologia das ausências opera a (des)globalização do local em relação à globalização hegemônica e explora a possibilidade de o (re)globalizar como forma de globalização contra-hegemônica; o 'improdutivo', nesse domínio confronta o que a ortodoxia produtivista capitalista busca ocultar, ao recuperar e valorizar sistemas alternativos de produção das organizações econômicas populares, cooperativas de trabalhadores, empresas autogeridas da economia solidária e, com isso, amplia o espectro da realidade social pela experimentação 
e pela reflexão sobre alternativas econômicas realistas para uma sociedade mais justa.

Segundo Nunes (2008, P. 60):

A contribuição de Santos para o debate epistemológico do Norte [...] caracteriza-se pela identificação de um conjunto de processos e de manifestações de crise que são interpretados no quadro de uma crise mais geral do projeto da modernidade. Uma compreensão do mundo que não se esgota na compreensão ocidental do mundo.

A constituição do campo da saúde coletiva situa-se no campo de disputa epistemológica ao promover a emergência e visibilidade de outros saberes, populares, de povos tradicionais, até então desqualificados, pelo monopólio do saber da ciência moderna, como pensamentos não científicos, e muitas vezes objeto de um verdadeiro epistemicídio (SANTOS, 1998).

No que se refere à epistemologia o pensamento abissal funda-se no que Santos (2007A) designa de linha abissal epistemológica que distingue saberes científicos daqueles da 'não ciência', e prossegue na desqualificação, seja pela apropriação de alguns desses saberes, seja eliminando-os através de diferentes formas de epistemicídio (NUNES, 2008).

A emergência da saúde coletiva permite escapar dos cânones epistemológicos hegemônicos da ciência moderna, valoriza práticas e saberes produzidos coletivamente, abrindo caminho para uma justiça cognitiva ao se contrapor à distribuição não equitativa de conhecimentos, em suas múltiplas formas, a projetos tanto de apropriação privada de conhecimentos e saberes como, a desqualificação, eliminação desses saberes.

A transformação do saber e do conhecimento em algo que pode ser objeto de apropriação privada, separado dos que o produzem, transportado, comprado, vendido, sujeito à forma de direito de propriedade estranhas ao contexto em que esse saber ou conhecimento foi produzido e apropriado coletivamente corresponde, de fato, a uma operação de eliminação obscurantista de saberes e de experiências em nome da sua racionalização e da sua subordinação aos cânones epistemológicos associados à ciência moderna. Esse resultado pode ser obtido, assim, através de dois caminhos: o da assimilação da destruição física, material, cultural e humana, e o da incorporação, cooptação. (SANTOS, 2007B, P. 9).

O projeto civilizatório do MRSB contribuiu para que as experiências de vida dos oprimidos lhes sejam inteligíveis por via do que Santos (2010) denomina uma epistemologia das consequências.

A ecologia de saberes não concebe os conhecimentos em abstrato, mas antes como práticas de conhecimento que possibilitam ou impedem certas intervenções no mundo real e deixa de conceber a ciência como referência ou ponto de passagem para o reconhecimento de todos os saberes e conhecimentos. Deste modo, é a própria concepção do que é a epistemologia que é radicalmente transformada. Um pragmatismo epistemológico é, acima de tudo, justificado pelo fato de as experiências de vida dos oprimidos thes serem inteligíveis por via de uma epistemologia das consequências. No mundo em que vivem, a consequência vem sempre primeiro que as causas. (SANTOS, 2007A, P. 28).

Podemos caracterizar o processo do MRSB como um processo de resistência contra as linhas abissais e parte de uma articulação latinoamericana de saúde pública/ medicina social e a nascente saúde coletiva, na perspectiva de tecer um pensamento pós-abissal em escala global.

Muitas das experiências subalternas de resistência são locais ou foram localizadas e assim tornadas irrelevantes ou inexistentes pelo conhecimento abissal moderno, o único capaz de gerar experiências globais. Contudo, uma 
vez que a resistência contra as linhas abissais tem de ter lugar a uma escala global, é imperativo desenvolver algum tipo de articulação entre as experiências subalternas através de ligações locais globais. Para ser bem-sucedida, a ecologia de saberes tem de ser trans-escalar. (SANTOS, 2007A, P. 27).

Consideramos a experiência do MRSB como relevante contribuição do Sul global na perspectiva de uma epistemologia do Sul, e, de uma articulação local/global de globalização contra-hegemônica.

O pensamento pós-abissal pode ser sintetizado como um aprender com o Sul usando uma epistemologia do Sul. Confronta a monocultura da ciência com uma ecologia de saberes. (SANTOS, 2007A, P. 22).

\section{Movimento da Reforma Sanitária Brasileira: dialogando e aprendendo com o Sul}

Ao recordar o MRSB o faremos de um lado, pelo (re)conhecimento de seu significado como experiência que traz à tona um Brasil popular, protagonista indiscutível da construção de políticas públicas, dos direitos sociais e políticos no País, de forma democrática, participativa, com suas diversas expressões locais, como os movimentos comunitários pelo direito à saúde, herdeiros de tantos outros, que revelam um Brasil, não da falta, mas de uma potência criativa. Por outro lado, pela sua insubordinação intelectual e capacidade política de realizar o milagre de iniciar algo inteiramente novo, de escapar do previsível, no sentido trabalhado por Arendt $(1990,2009)$ e Souto (2012), construindo no processo constituinte de 1988, um projeto civilizatório de transformações sociais e, do campo da saúde, na contramão da tendência mundial, hegemonizada por propostas de reformas de cunho neoliberal.

A ditadura militar com seu processo de modernização autoritária (SINGER, 1976; BRESSERPEREIRA, 2014) adota uma estratégia de aliança entre o governo, o capitalismo nacional e o internacional e, implementa uma política de desenvolvimento econômico que exclui os trabalhadores. O chamado milagre brasileiro, crescimento econômico com arrocho salarial e perda do poder aquisitivo do salário-mínimo, enfatiza uma histórica concentração de renda, aumento das desigualdades sociais e também o aumento da dívida externa do País. Na área da saúde, a configuração é de uma cisão entre a saúde pública e individual, sendo o Ministério da Saúde, fragilizado financeiramente, responsável pela promoção da saúde, prevenção de doenças, pelo enfrentamento das grandes endemias e atendimento aos chamados indigentes, e o Ministério da Previdência, através do Instituto Nacional de Assistência Médica da Previdência Social (Inamps), responsável pela atenção individual aos portadores de carteira de trabalho. Nesse período, a saúde transforma-se em bem de consumo com o fomento à expansão do mercado de planos e seguros-saúde, e correspondente deterioração dos serviços públicos.

Como comenta Escorel (2008, P. 324)

Até 1964, a assistência médica previdenciária era prestada, principalmente, pela rede de serviços próprios dos IAPs, compostos por hospitais, ambulatórios consultórios médicos. A partir da criação do INPS, alegando a incapacidade de a rede própria de serviços fornecer assistência médica a todos os beneficiários, foi priorizada a contratação de serviços de terceiros. A orientação de privilegiar o setor privado de serviços de saúde, foi no âmbito da previdência social, a expressão da diretriz estabelecida na Constituição de 167 e reiterada na Constituição de 1969, consubstanciada no Decreto-Lei n. 200/1968 sobre a Reforma Administrativa. 
$\mathrm{O}$ arbítrio se difunde em exemplos como a interferência da censura na divulgação de dados sobre a epidemia de meningite e, o emblemático 'massacre de Manguinhos', a cassação dos direitos políticos e aposentadoria compulsória de dez pesquisadores da Fundação Oswaldo Cruz, sob a égide do AI-5. Não por acaso, o lema chave do MRSB foi: 'Saúde é Democracia'.

Em um contexto de aprofundamento da crise política, econômica, social, de legitimidade da ditadura militar, cresce e se irradiam por todo o País as mobilizações pela redemocratização, pela constituinte e pelas eleições diretas para presidente da república. As iniciativas de mobilização se multiplicam como as memoráveis greves do ABC paulista em maio de 1978, os movimentos comunitários País afora, com sua pauta de direitos sociais de cidadania como saúde, moradia, transporte, educação cultura, o movimento Diretas Já, que culmina num histórico comício de mais de um milhão de pessoas na Candelária, Rio de Janeiro, em 10 de abril de 1984. No campo, o movimento de trabalhadores rurais luta pelo direito à terra e pela reforma agrária.

O movimento estudantil e a academia reforçam uma agenda de reformas democráticas para a Assembleia Nacional Constituinte. Estava posto o desafio de elaborar uma Constituição que encarnasse o espírito da época, que traduzisse a potência política do momento em direitos de cidadania. As possibilidades aí inauguradas são consistentes e, não é por mero acaso, que a Constituição de 1988 torna-se a Constituição Cidadã e a República é denominada Nova República. A Constituição Cidadã de 1988 inaugura um novo momento na cena política do País, da democracia de massas, a aprovação do voto do analfabeto realiza a inclusão de todos os brasileiros no processo político. São estabelecidos os direitos sociais universais de cidadania e, incorporados no seu texto elementos de democracia direta, participativa, para além da democracia representativa.
No mesmo período prospera em nível mundial um debate no campo da saúde motivado tanto pelos altos custos da assistência médica, sem o correspondente impacto sobre as condições de saúde da população, quanto pelo fato da crescente participação dos governos no financiamento, seja nos sistemas públicos ou nos de natureza privada. Com importante influência dos Estados Unidos nasce então a 'medicina preventiva', como método a ser incorporado à prática médica liberal visando racionalizar gastos e produzir impactos sobre as condições de saúde.

A crise fiscal do período 1970/80 repercute globalmente na agenda da saúde, e, como comenta Almeida (2008), vários autores de origens políticas e ideológicas distintas, convergem para um mesmo diagnóstico formulando um homogêneo discurso conservador que se opõe às políticas universais com uma agenda de gerenciamento da crise através do receituário de ajustes macroeconômicos de organismos internacionais (Banco Mundial, Fundo Monetário Inernacional), cortes de gastos e menos Estado. Essa agenda de reformas da saúde persiste até hoje, subordinada à perspectiva do projeto neoliberal de construção de uma sociedade orientada para o mercado.

Ao mesmo tempo, a influência de governos sociais-democratas de países europeus produz renovação da Organização Mundial de Saúde (OMS), sendo eleito para presidi-la (1973-1988) o médico dinamarquês Halfdan T. Mahler. Nesse contexto, a OMS organiza a XXX Assembleia Mundial da Saúde, em 1977, quando é lançado o movimento Saúde Para Todos no Ano 2000. Como marco inicial, é realizada em setembro de 1978 a Conferência Internacional sobre Cuidados Primários de Saúde na cidade de Alma-Ata, no Cazaquistão, que reafirma a saúde como um direito humano fundamental e como uma das mais importantes metas mundiais para a melhoria das condições de vida e redução das desigualdades. Coloca-se, então, uma visão crítica tanto, aos programas verticais 
desenvolvidos na América Latina e África, como, ao hegemônico modelo biomédico de atenção à saúde enfatizando a determinação social do processo saúde-doença.

O MRSB significa, nesse contexto, uma experiência contra-hegemônica, na contramão da tendência hegemônica de reformas de cunho neoliberal e, afirma a indissociável conexão entre a reforma democrática/republicana da saúde e um projeto de desenvolvimento inclusivo para o País.

A compreensão política do processo, o espírito libertário, a ousadia intelectual criativa de pensar o nunca antes pensado, a ação concertada, permeiam as várias iniciativas e, assim, o movimento sanitário ganha forma e, se delineia o projeto político civilizatório da Reforma Sanitária Brasileira.

Como diz Cordeiro (2004, P. 345)

No turbilhão de autores, discutidos no fim de tarde à beira de alguma birosca da moda, iam sendo urdidas ideias, projetos, soluções nem sempre exequíveis e [...] da confluência entre a Academia e a práxis, entre as críticas ao complexo médico-empresarial e o exercício de propostas de descentralização e municipalização, brotavam rabiscos de alternativas que, muitas vezes, se traduziam em novos cursos, seminários, documentos, reuniões no Sindicato dos médicos ou no Centro Brasileiro de Estudos da Saúde (Cebes). Um momento estratégico para a organização da Reforma Sanitária foi o 1o Simpósio sobre Política Nacional de Saúde, com debate e aprovação do documento a 'Questão democrática na área da saúde', apresentado pela diretoria nacional do Cebes, transformando-se em documento base para as conclusões finais do encontro.

O caráter crítico do documento aprovado no I Simpósio de Política Nacional de Saúde em outubro de 1979 ao regime autoritário pode ser visto no excerto:

Política que substitui a voz da população pela sabedoria dos tecnocratas e pelas pressões dos diversos setores empresariais; política de saúde que acompanha em traçado as linhas gerais do posicionamento socioeconômico do governo-privatizante, empresária e concentrada renda, marginalizando cerca de $70 \%$ da população de benefícios materiais e culturais do crescimento econômico [...]. Política de saúde, enfim, que esquece as necessidades reais da população e se norteia exclusivamente pelos interesses de minoria constituída e, confirmada pelos donos das empresas médicas e gestores da indústria da saúde em geral. (CEBES, 1980, P. 47).

Nesse documento como observa Cordeiro (2004), já estão contidos alguns dos princípios que seriam adotados pela reforma sanitária como direito universal e inalienável, a determinação social do processo saúde/doença, a descentralização, regionalização, hierarquização, participação popular e controle social e entre as medidas iniciais se destaca "Criar o Sistema Único de Saúde" (CORDEIRO, 2004, P. 346). E ressalta um ponto fundamental:

[...] negador de uma solução meramente administrativa ou 'estatizante'. Evita-se [...] uma participação de tipo centralizador, tão cara ao espírito corporativo e tão apto a manipulações que cooptam um Estado fortemente centralizado e autoritário, como tem sido tradicionalmente o estado brasileiro. (CORDEIRO, 2004, P. 47).

\section{Conferência Nacional de Saúde - uma Constituinte Popular de Saúde - tecendo uma ecologia de saberes}

Nessa teia de iniciativas vai se configurando um movimento enraizado e organizado nacionalmente. São criados múltiplos ambientes de encontros, profissionais, comunitários, legislativos, debates, fóruns locais, regionais, nacionais, plenárias de saúde. As discussões proliferam em simpósios, seminários, cursos e, criam-se veículos de comunicação 
alternativos. Esse amplo processo de mobilização e construção coletiva do direito à saúde se expande tanto em pré-conferências estaduais como em pós-conferências nacionais temáticas com uma pluralidade de temas como as Conferências Nacionais da Saúde da Mulher (10-13/10/1986), Saúde da População Indígena (26-24/11/1986), Saúde do Trabalhador (1-5/12/1986) Saúde Mental (25-28/06/1987). Esse rico processo participativo tem como momento culminante a VIII Conferência Nacional de Saúde (17-21/03/1986) com a participação de cerca de 5 mil pessoas, a metade oriunda de movimentos sociais, uma verdadeira Constituinte Popular da Saúde, uma celebração emocionante de felicidade pública, uma festa popular multicultural democrática/republicana. Num clima de efervescente criatividade e compromisso, povos indígenas, movimento feminista, grupos de pacientes, movimentos comunitários, trabalhadores rurais e urbanos, debatem durante cinco dias em cento e trinta e cinco grupos de trabalho, e numa assembleia final que durou mais de 24 horas, aprovam o projeto político da Reforma Sanitária Brasileira, que foi base do capítulo da saúde na Constituição de 1988. É bom lembrar que não foram poucos os que apostaram que naquela 'balburdia' polifônica nada se produziria. Também no processo da Constituinte, o movimento organiza espaços inovadores como a Plenária das Entidades de Saúde e a Comissão Nacional da Reforma Sanitária que transformou o texto da Constituição na Lei Orgânica da Saúde, Lei no 8.080 de 19/09/1990.

O significado político da VIII Conferência Nacional de Saúde transcende o âmbito da luta pelo direito à saúde e está no âmbito dessas práticas que marcam as possibilidades políticas de um tempo. Como bem compreende Arouca (1986, P. 35) na sua fala de abertura à VIII Conferência, 'Democracia é Saúde':

Inicialmente eu também gostaria de dizer que, infelizmente por condições absolutamente arquitetônicas, existe um fosso entre a mesa e a plateia, quando na realidade toda a nossa intenção, ao contrário de colocar jacarés, crocodilos e demais espécies peçonhentas no fosso, sempre foi de conseguir uma integração bastante clara, transparente, objetiva na discussão das questões de política de saúde. Por isso, eu gostaria de solicitar que na realidade nós estivéssemos o mais próximo possível nessa discussão sobre políticas de saúde. Em segundo lugar, eu gostaria também de pedir desculpas aos sanitaristas, aos médicos, aos profissionais da área, aos pesquisadores, aos funcionários que trabalham no Ministério da Saúde, mas, na realidade, hoje, nesta 8a Conferência Nacional de Saúde, acho que temos um convidado, um participante que conseguiu um lugar nesta Conferência, com bastante sacrifício, e que é a sociedade brasileira organizada. Eu acho que é muito para eles que eu gostaria, hoje, quase que dedicar estas palavras. Acho que o fato de estar aqui na $8^{a}$ Conferência Nacional da Saúde, a representação de confederações nacionais de trabalhadores, de estarem aqui representados e pedindo direito à voz e a voto o movimento popular da saúde de Recife, pelo fato de estarem aqui participando associações de bairro e outras entidades da sociedade brasileira como a CNBB, a ABI, a $O A B$, enfim o conjunto de entidades que conseguimos identificar num mapeamento quase que exaustivo da sociedade brasileira, eu gostaria de considerá-los como membros privilegiados desta 8 a Conferência Nacional da Saúde. E a eles quero dedicar a discussão sobre essa questão de 'Democracia é Saúde' que vamos enfrentar.

Cabe ressaltar que a capacidade de pensar o novo, a coragem de correr riscos, de experimentar, de constituir espaços públicos de participação ativa e radicalmente democrática/republicana, foi o que permitiu desbravar novos caminhos, teóricos e políticos que lastrearam a fundação de algo inédito, o 
projeto da Reforma Sanitária Brasileira.

Essas características fundadoras do MRSB permitem, na nossa opinião, compreendê-lo como parte constituinte e constitutiva de um processo de globalização alternativa, de um pensamento pós-abissal e de exercício de uma ecologia de saberes.

\section{O direito à saúde: entre o passado e o futuro - o giro de volta aos valores do projeto civilizatório do Movimento da Reforma Sanitária Brasileira}

Pensamos ser crucial para enfrentar os desafios à efetivação do direito à saúde, proclamado na Constituição de 1988, realizarmos um giro de volta aos valores fundantes do MRSB, ou seja, compreendê-los na perspectiva de um projeto civilizatório e político de reforma democrática/participativa e republicana do Estado e sociedade brasileiros e, não o rebaixar a uma mera reforma gerencial, burocrática, administrativa da área da saúde. Como comenta Arouca (2002, P. 19) "nós temos que retomar o conceito de reforma sanitária para retomar políticas dentro do sistema sem burocratizá-lo".

A capacidade do MRSB de se contrapor ao hegemônico projeto neoliberal, com sua agenda de primazia do mercado no campo da saúde, só foi possível, pela ação política concertada, pela potência de um pensamento crítico que permitiu escapar do previsível e, inaugurar algo inteiramente novo, o milagre do novo começo, tal como o concebe Arendt $(1999,2009)$. Na mesma direção expõe Teixeira (2009, P. 46)

O movimento que impulsionou a Reforma Sanitária Brasileira colocou como projeto a construção contra-hegemônica de um novo patamar civilizatório, o que implica uma profunda mudança cultural, política e institucional capaz de viabilizar a saúde como bem público.

Como pano de fundo para melhor compreendermos os desafios que se colocam buscamos luzes nas reflexões de Arendt (1990) sobre a crise da modernidade ocidental e, em Santos (2010) sobre a crise do contrato social da modernidade e a emergência do fascismo social.

Para Arendt (1990), a cadeia de catástrofes deflagradas pela Primeira Guerra Mundial, com o surgimento dos regimes totalitários, com o genocídio, a descartabilidade humana na produção industrial do extermínio, a tragédia e os horrores das desnacionalizações de populações inteiras e as desnaturalizações em massa a criar uma multidão de apátridas, sem direito a ter direitos, descortinou uma realidade dos sem nação, sem território, sem cidadania, expulsos da humanidade, refugo de todos os Estados Nações, evidenciando a falácia da promessa das Declarações de Direitos Humanos surgida com o advento das Revoluções da Era Moderna e a crise do seu corpo político, o Estado-Nação.

É como se a humanidade se houvesse dividido entre os que acreditam na onipotência humana (e que julgam ser tudo possível a partir da adequada organização das massas num determinado sentido) e os que conhecem a falta de qualquer poder como a principal experiência de vida. (ARENDT, 1990, P. 11).

Para ela, o século XX presenciou o declínio do político, seja pela violência devastadora do fenômeno totalitário, seja pela transformação estrutural da esfera pública, privatizada pelo primado do econômico, da necessidade do 'ganhar a vida', reduzindo o cidadão a trabalhador/consumidor. As sociedades administradas de massas, com sua uniformização e isolamento dos indivíduos. A ação, atributo da política, para Arendt (1990), é substituída pelo comportamento repetitivo, previsível, a hegemonia da racionalidade do 
consumo em nome do consumo, produzindo uma sociedade de indivíduos voltados para si mesmos, sua satisfação e, se protegendo das hostilidades do mundo, quando o ponto central de toda a política é o comprometimento com o mundo pela ação concertada.

Em Santos (2010) destacamos a reflexão sobre a crise contemporânea do contrato social, que tem presidido a organização da sociabilidade econômica, política e cultural das sociedades modernas e, a emergência do fascismo social, uma nova forma de estado de natureza que prolifera à sombra da crise do paradigma do contrato social que tem presidido a organização da sociabilidade econômica, política e cultural das sociedades modernas.

Como comenta Santos (2010), esse paradigma do contrato social do Estado-Nação Moderno, de produção de quatro bens públicos: legitimidade de governar, bem-estar econômico e social, segurança e identidade cultural, com todas as suas variações de critérios de inclusão/exclusão, vem atravessando um período de grande turbulência, tão profunda, que aponta para uma convulsão de época e uma transição paradigmática. As transformações do contrato social têm produzido diferentes e profundas mudanças em seus três dispositivos operacionais, a socialização da economia, a politização do Estado, a nacionalização da identidade cultural que são decorrentes, direta ou indiretamente, do consenso liberal.

O consenso econômico neoliberal, o chamado Consenso de Washington de 1989, embora desgastado por contradições, oposições e críticas, configurou-se como um contrato social entre os países capitalistas centrais que, estabeleceu as grandes transformações político-econômicas do capitalismo mundial nas últimas décadas. Este consenso expresso em dez regras, entre as quais disciplina fiscal, redução dos gastos públicos, abertura comercial, juros de mercado, câmbio de mercado, privatização das estatais, desregulamentação das leis econômicas e trabalhistas, direito à propriedade intelectual, apresentadas como condições inexoráveis, forças naturais, as quais os outros países deviam se subordinar.

Este consenso neoliberal com seus significados, entre outros, de retirada do Estado da regulação social, de privatização dos serviços públicos é tratado por Santos (2010) como governo indireto, quando poderosos atores não estatais adquirem o controle sobre as vidas e o bem-estar de vastas populações, seja pelo controle dos cuidados de saúde, da terra, das sementes, da floresta ou da qualidade ambiental. A esse regime social de relações de poder extremamente desiguais que permite o poder de veto dos mais fortes sobre a vida e maneira de viver dos mais fracos é descrito como ascensão do fascismo social, caracterizado em lógicas, aqui brevemente apresentadas. Como por exemplo: 'o fascismo do apartheid social', a segregação social dos excluídos, dividindo zonas selvagens urbanas, do estado natureza hobbesiano, de guerra civil interna, e, zonas civilizadas do contrato social que vivem sob ameaça das selvagens; 'o fascismo contratual', o projeto neoliberal de transformação do contrato de trabalho em contrato de direito civil, frequente nas privatizações dos serviços públicos; 'o fascismo territorial', a retirada do Estado do controle de territórios onde atuam atores de forte poder econômico e patrimonial que exercem a regulação social sem a participação e contra os interesses de seus habitantes; 'o fascismo financeiro', a mais violenta forma de sociabilidade fascista, a lógica de lucro especulativo que confere ao capital financeiro um poder discricionário, praticamente incontrolável, poderoso o suficiente para abalar em segundos a economia real ou a estabilidade política de qualquer país. Como informa Santos de cada cem dólares que circulam diariamente no mundo, noventa e oito pertence a essa economia de cassino e, apenas dois por cento à economia real.

As consequências do projeto neoliberal 
para a humanidade são devastadoras como mostra o recém-divulgado estudo da organização não governamental britânica Oxfam (Oxford Comittee for Famine Releaf) sobre a evolução da desigualdade no mundo, com base em dados do Credit Suisse. O estudo mostra que a parcela da riqueza mundial nas mãos do $1 \%$ mais rico da humanidade cresceu $44 \%$, do total em 2009 para $46 \%$ em 2014 . A continuar esse processo de concentração, a projeção é de que o $1 \%$ mais rico terá mais de $50 \%$ dos bens e patrimônios existentes no mundo e pode, já em 2016 concentrar uma riqueza maior do que o resto dos $99 \%$ combinados. O estudo também mostra que a concentração é mais intensa no topo, como o fato de que em 2010 as 80 pessoas mais ricas do planeta tinham uma riqueza conjunta de US\$ 1,3 trilhão e em 2014 o valor já era de US\$ 1,9 trilhão. Ao mesmo tempo o patrimônio da metade mais pobre do mundo é menor do que em 2009. Outro dado mostra que em 2013/2014 a riqueza do $1 \%$ está concentrada em setores como finanças e seguros com grande crescimento do mercado global da saúde, serviços médicos e indústria farmacêutica (CALEIRO, 2015).

No Brasil, o processo democrático participativo que impulsionou a conquista da Constituição Cidadã de 1988, plataforma para o enfrentamento das desigualdades estruturais do País (BARROS; HENRIQUES; MENDONÇA, 2000), transitou entre forças políticas contraditórias dificultando a afirmação de um projeto desenvolvimentista com inclusão social e distribuição de renda.

A desintegração do pacto democrático popular, como o denomina Bresser-Pereira (2014), que presidiu a transição democrática, interrompe a oportunidade de retomada do projeto social desenvolvimentista, repetindo o problema de desacelerações e crises econômicas cíclicas do desenvolvimentismo brasileiro, conforme analisa Fiori (2015).

A partir da década de 1990, o projeto neoliberal chega tardiamente ao Brasil, e, sob a insígnia do fim da era Vargas se desarticula o
Estado regulador com a proposta de centralidade do mercado e Estado mínimo. Mesmo com fortes resistências de movimentos sociais e políticos, se implementam políticas de informalização e precarização das relações de trabalho, privatização irresponsável do patrimônio público, subalternidade da política externa e financeirização da economia.

A ascensão de governos pós-neoliberais na América Latina nos anos 2000, representou um contraponto importante à hegemonia neoliberal liderada pelos Estados Unidos, considerada por Chomsky (2015) como uma das resistências mais importantes ao assalto neoliberal no mundo. A criação da Unasul (União das Nações Sul-Americanas), Celac (Comunidade de Estados LatinoAmericanos e Caribenhos), do bloco econômico do Brics (Brasil, Rússia, Índia, China e África do Sul) são iniciativas representativas de um complexo processo de construção de alternativas a hegemonia neoliberal.

O Brasil a partir de 2003 realiza uma mudança na perspectiva de um projeto de desenvolvimento com inclusão social e a implementação de políticas de redução das desigualdades, com a retirada de milhões de pessoas da miséria, aumento real do salário-mínimo, menor taxa de desemprego da série histórica do Instituto Brasileiro de Geografia e Estatística (IBGE) com impactos, entre outros, sobre os determinantes sociais da saúde.

Realizamos essa breve contextualização para melhor compreendermos os desafios colocados à realização efetiva do direito universal à saúde, sua inerente articulação com outro padrão de desenvolvimento e, suas conexões com o aprofundamento de uma radical reforma democrática participativa do Estado e sociedade brasileira, que promova a consolidação do projeto de desenvolvimento inclusivo e solidário capaz de enfrentar as desigualdades estruturais do País na perspectiva dos valores do projeto civilizatório do MRSB e, do que Santos (2010) denomina 
a reinvenção solidária e participativa do Estado.

A atualidade da disputa de projetos no campo da saúde, a nível global/local, é clara, como revela o Relatório Mundial da Saúde de 2010 (OMS, 2010), 'Financiamento dos Sistemas de Saúde: o Caminho para a Cobertura Universal', uma clara manifestação do pensamento neoliberal de restrição de direitos, focalização das políticas sociais, subordinação da saúde e, da vida dinâmica do mercado, difundido em uma série de artigos sobre o tema, publicados na prestigiada revista inglesa 'Lancet', um dos quais dizia que 'cobertura universal de saúde' corresponderia a uma terceira transição sanitária global. Em dezembro de 2012 o tema foi levado à Assembleia Geral da Organização das Nações Unidas (ONU) e incorporado como um dos itens da Resolução A/RES/67/81 - Saúde Global e Política Externa (NORONHA, 2013).

O Brasil, em que pese os avanços que nos colocam na condição de referência latino-americana de sistema universal de saúde, como reconhece a Alames (Associação Latino-Americana de Medicina Social) (ALAMES; CEBES, 2013) convive com desafios estruturais para a consolidação do direito universal à saúde que repercutem nos desafios à construção de um outro padrão de desenvolvimento tão bem sintetizado por Furtado (1998, P. 64-65):

Devemos nos empenhar para que esta seja a tarefa maior dentre as que preocuparão os homens no correr do próximo século: estabelecer novas prioridades para a ação política em função de uma nova concepção de desenvolvimento, posto ao alcance de todos os povos e capaz de preservar o equilíbrio ecológico. O espantalho do subdesenvolvimento deve ser neutralizado. O principal objetivo da ação social deixaria de ser a reprodução dos padrões de consumo das minorias abastadas para ser a satisfação das necessidades fundamentais do conjunto da população e a educação concebida como desenvolvimento das potencialidades humanas nos planos ético, estético e de ação solidária. A criatividade humana, hoje orientada de forma obsessiva para a inovação tecnológica a serviço da acumulação econômica e do poder militar, seria reorientada para a busca do bem-estar coletivo, concebido este como a realização das potencialidades dos indivíduos e das comunidades vivendo solidariamente.

A busca para superação das desigualdades estruturais e dos riscos do fascismo social pela erosão do contrato social exige uma compreensão que nos impulsione a escapar do previsível e realizar o milagre do novo começo pela ação concertada (ARENDT, 1990, 2009), da ação não conformista, rebelde, a ação-com-clinamen como denomina Santos (2010), na perspectiva da reinvenção solidária e participativa do Estado pós-neoliberal, do Estado de Bem-Estar Social.

São múltiplas as dimensões abordadas por Santos (2010) da reinvenção solidária e participativa do Estado superando sua privatização patrimonialista, como a refundação democrática das relações entre administração pública e organizações não governamentais, entre democracia representativa e participativa, entre sociabilidades alternativas. Uma das condições destacadas diz respeito à democracia redistributiva com a afirmação de uma solidariedade fiscal, e uma fiscalidade participativa.

Apesar de o Brasil estar realizando esforços, já significativos, na busca da redistribuição da riqueza produzida são notórias as resistências internas na direção de outro padrão tributário, progressivo, de uma maior visibilidade e transparência financeira, que permitam avançar para um padrão de justiça tributária, como a taxação de grandes fortunas e, assim, identificar as barreiras ao desenvolvimento solidário, como, a financeirização da economia reorientando recursos para políticas sociais estratégicas ao enfrentamento das desigualdades, como o direito universal à saúde. 
Os desafios são complexos, pois trata-se de enfrentar a hegemonia da lógica do mercado no campo da saúde, sua colonização pelo modelo biomédico de atenção com as consequentes desigualdades econômicas, culturais, epistemológicas, expressas em situações persistentes como os exemplos do subfinanciamento crônico do sistema público de saúde e a injustiça tributária na transferência de recursos públicos para subsidiar os lucros do mercado de planos de saúde. Os dados mostram que apesar de o Brasil ter avançado de 4,1\% em 2000 para $7,9 \%$ em 2012, do orçamento nacional para a saúde, persistem não só o subfinanciamento, como a iniquidade revelada no volume da renúncia fiscal em 2006 de $\mathrm{R} \$$ 12,5 bilhões equivalentes a $30 \%$ dos gastos do governo com saúde (OKCÉ-REIS, 2012).

O giro de volta aos valores contra-hegemônicos do MRSB, como a defesa intransigente da saúde como direito universal de cidadania e o exercício de uma ecologia de saberes, proporcionada pela invenção/ construção do campo da saúde coletiva, são valores que podem nos iluminar no aprofundamento dessa reinvenção solidária e participativa do Estado.

Um dos temas que já vem sendo objeto dessa reinvenção no campo da saúde é a atenção ao parto e nascimento, uma celebração da vida, que colonizada pelo modelo industrializado (SANTOS, 2002; SOUTO, 2012) de atenção, transformou o Brasil em recordista mundial de cesarianas desnecessárias (LEAL, 2014). O revigoramento do movimento de mulheres, casais e profissionais pelo giro de volta ao protagonismo das mulheres, nesse momento único de suas vidas, vem reescrevendo uma nova narrativa de escolha ativa das mulheres e casais com implicações profundas na reorientação radical do modelo de atenção.

Nesse momento de mudança de época nada como revisitar o que Santos (2010) chama o otimismo trágico e transgressivo da subjetividade de Nuestra América, encarnada em tantos como José Marti, Oswald de Andrade no Manifesto Antropofágico, Darci Ribeiro no Povo Brasileiro, Zumbi de Palmares, Nise da Silveira, na capoeira, no carnaval, na música, nas danças, nas diversas artes, saberes, sabores, lutas, em tantas e genuínas manifestações políticas e culturais como, o próprio MRSB.

Nuestra América que antes de se tornar um projeto político é uma forma de subjetividade e de sociabilidade. É uma forma de ser e de viver permanentemente em trânsito e na transitoriedade, cruzando fronteiras, criando espaços de fronteiras, habituada ao risco como o qual viveu longos anos, muito antes de o Norte global ter inventado a 'sociedade do risco' [...] - habituada a viver com um nível baixo de estabilização das expectativas causado pelas brutais desigualdades sociais e pela colonialidade do poder. Mas paradoxalmente, também capaz de tirar do risco de viver a pulsão para um optimismo visceral perante a potencialidade coletiva. (SANTOS, 2010, P. 204).

Que a pulsão criativa revigore a mobilização em torno das bandeiras civilizatórias do MRSB como a vigorosa XV Conferência Nacional de Saúde em 2015, o Movimento Nacional em Defesa da Saúde Pública, o Saúde Mais 10, as articulações protagonizados por movimentos históricos da reforma sanitária como Centro Brasileiro de Estudos de Saúde (Cebes), Associação Brasileira de Saúde Coletiva (Abrasco), pelo Conselho Nacional de Saúde (CNS), em defesa e pela consolidação do Sistema Único de Saúde (SUS) como sistema universal de saúde. Momento privilegiado para ressignificar o pensamento pós-abissal do MRSB, afirmando o seu caráter de parte constitutiva e constituinte de uma globalização alternativa, uma sociedade inclusiva, radicalmente democrática, participativa, onde, prospere uma ecologia de saberes. 


\section{Referências}

ALMEIDA, C. Reformas de sistemas de saúde: tendências internacionais, modelos e resultados. In: GIOVANELLA, L. et al. (Org.). Políticas e sistemas de saúde no Brasil. Rio de Janeiro: Fiocruz, 2008.

\section{ASSOCIAÇÃO LATINO-AMERICANA DE MEDICINA SOCIAL (ALAMES). CENTRO BRASILEIRO DE ESTUDOS EM SAÚDE (CEBES). Afirmación de los sistemas universales de salud en Latinoamerica. Congresso brasileiro de política, planejamento e gestão em saúde, 2., [Internet], 1 out. 2013. Disponível em: <http://cebes.org.br/site/wp-content/uploads/2014/03/ afirmacion-de-los-sistemas-universales-de-salud-en- latinoamerica.pdf $>$. Acesso em: 15 set. 2014.}

ANDRADE, O. A utopia antropofágica. São Paulo: Globo, 1990.

ARENDT, H. A condição humana. São Paulo: Forense Universitária, 1999.

Entre o passado e o futuro. São Paulo: Perspectiva, 2009

As origens do totalitarismo. São Paulo: Companhia das Letras, 1990.

AROUCA, A. S. Democracia é saúde. In: CONFERÊNCIA NACIONAL DE SAÚDE, 8., 1986, Brasília. Anais... Brasília: DF, 1986. p. 35-42.

O dilema preventivista. São Paulo: Unesp: Rio de Janeiro: Fiocruz, 2003.

Radis entrevista: Sérgio Arouca. Radis comunicação e saúde, Rio de Janeiro: Fiocruz, n. 3, out. 2002.

BARROS, R. P.; HENRIQUES, R.; MENDONÇA, R. A estabilidade inaceitável: desigualdade e pobreza no Brasil. In: HENRIQUES, R. (Org.). Desigualdade e pobreza no Brasil. Rio de Janeiro: Ipea, 2000.

BRESSER-PEREIRA, L. C. A construção política do Brasil. São Paulo: Editora 34, 2014.
CALEIRO, J. P. 4 gráficos que mostram a explosão da desigualdade no mundo. Exame.com, [Internet], jan. 2015. Disponível em: <http://exame.abril.com.br/ economia/noticias/4-graficos-que-mostram-a-explosaoda-desigualdade-no-mundo $>$. Acesso em: 10 jun. 2015.

\section{CENTRO BRASILEIRO DE ESTUDOS DE SAÚDE}

(CEBES). A questão democrática na saúde. Saúde em

Debate, Rio de Janeiro, v. 9, p. 47-48, 1980.

CHOMSKY, N. Dizia-se que os EUA são um Estado de um só partido (o partido dos negócios) com duas facções (democratas e republicanos), O diário.info, 3 mar. 2015. Entrevista concedida a Miguel Mora. Disponível em: $<$ http://www.odiario.info/?p=3573>. Acesso em: 15 jun. 2015.

CORDEIRO, H. O instituto de medicina social e a luta pela reforma sanitária: contribuição à história do SUS. Physis, Rio de Janeiro, v. 14, n. 2, p. 343-362, 2004.

ESCOREL, S. História das políticas de saúde no Brasil de 1964 a 1990: do golpe militar à reforma sanitária. In: GIOVANELla, L. et al. (Org.). Políticas e sistemas de saúde no Brasil. Rio de Janeiro: Fiocruz, 2008.

FIORI, J. L. Ciclos e crises. Valor econômico [Internet]. São Paulo, abr. 2015. Disponível em: < http://www.valor. com.br/opiniao/4028888/ciclos-e-crises $>$. Acesso em: 17 dez. 2015.

FURTADO, C. O capitalismo global. Rio de Janeiro: Paz e Terra, 1998.

LEAL, M. C. Nascer no Brasil: inquérito nacional sobre parto e nascimento. Rio de Janeiro: Fiocruz, 2012.

NORONHA, J. C. Cobertura universal de saúde: como misturar conceitos, confundir objetivos, abandonar princípios. Cad. Saude Publica, Rio de Janeiro, v. 29, n. 5, p. 847-849, maio 2013.

NUNES, J. A. O resgate da epistemologia. Revista Crítica de Ciências Sociais. Lisboa, n. 80, p. 45-70, mar. 2008. 
OCKÉ-REIS, C. O. SUS: o desafio de ser único. Rio de Janeiro: Fiocruz, 2012.

ORGANIZAÇÃO MUNDIAL DE SAÚDE (OMS).

Financiamento dos Sistemas de Saúde: o caminho para a cobertura universal. Disponível em: $<$ www.who.int/ whr/2010/whr10_pt.pdf>. Acesso em: 18 out. 2015.

PAIM, J. S. Reforma sanitária brasileira: contribuição para compreensão crítica. 2007. 300 f. Tese (Doutorado em Saúde Coletiva) - Instituto de Saúde Coletiva, Universidade Federal da Bahia, Salvador, 2007.

SANTOS, B. S. A gramática do tempo: para uma nova cultura política. São Paulo: Cortez, 2010.

Para além do pensamento abissal: das linhas globais a uma ecologia de saberes. Revista Crítica de Ciências Sociais, Lisboa, n. 79, p. 3-46, out. 2007a.

Reinventar a democracia. Lisboa: Gradiva, 1998.

Renovar a teoria crítica e reinventar a emancipação social. São Paulo: Boitempo, 2007b.
SANTOS, M. L. Humanização da assistência ao parto e nascimento. 2002. Dissertação (Mestrado em Saúde Pública) - Centro de Ciências da Saúde, Universidade Federal de Santa Catarina, Florianópolis, 2002.

SINGER, P. A crise do milagre. Rio de Janeiro: Paz e Terra, 1976.

SOUTO, L. O direito à saúde e a reforma democrática do Estado brasileiro: uma construção social republicana. Dissertação (Mestrado em Saúde Coletiva) - Instituto de Estudos em Saúde Coletiva, Universidade Federal do Rio de Janeiro, Rio de Janeiro, 2012.

TEIXEIRA, S. M. F. Retomar o debate sobre a reforma sanitária para avançar o Sistema Único de Saúde. Rev. adm. empres., São Paulo, v. 9, n. 4, p. 472-480, out./dez. 2009.

Recebido para publicação em julho de 2015

Versão final em outubro de 2015

Conflito de interesses: inexistente

Suporte financeiro: não houve 